\title{
ANALISIS POTENSI SUMBERDAYA IKAN PELAGIS DI PANTAI CIPARAGE JAYA KABUPATEN KARAWANG
}

\author{
Oleh:
}

Pigoselpi Anas, Iis Jubaedah, Sopyan D

Dosen Jurusan Penyuluhan Perikanan Sekolah Tinggi Perikanan

\begin{abstract}
ABSTRAK
Penelitian bertujuan untuk mengetahui tingkat penangkapan maksimum lestari (Maximum Sustainable Yield) dan tingkat penangkapan yang maksimum secara ekonomis (Maximum Economic Yield) sumberdaya ikan pelagis di Pantai Ciparage Jaya. Metode yang digunakan dalam penelitian ini adalah metode survei dan wawancara. Satuan penelitian adalah unit penangkapan mini purse seine. Hasil penelitian menunjukkan tingkat penangkapan maximum lestari (MSY) ikan pelagis kecil di perairan Ciparage Jaya adalah 2.996.716,6 kg/th, dan tingkat penangkapan yang maximum secara ekonomis (MEY) adalah 2.876.299 kg/th. Tingkat penangkapan nelayan rata-rata $2.686 .400 \mathrm{~kg} / \mathrm{th}$, berdasarkan potensi lestarinya (MSY) dan segi ekonomi (MEY) mendekati nilai optimum, sehingga tidak memungkinkan peningkatan upaya penangkapan dilakukan. Usaha (strategi) yang dapat dilakukan untuk meningkatkan taraf hidup keluarga nelayan adalah perbaikan dan peningkatan kualitas alat tangkap, sistem pasar yang dapat menjaga kestabilan harga, pengolahan ikan yang memberikan nilai tambah pada produksi perikanan, dan alternatif usaha budidaya.
\end{abstract}

Kata kunci : Sumberdaya, ikan pelagis, pantai Ciparage Karawang

\section{PENDAHULUAN}

\section{Latar Belakang}

Desa Ciparage Jaya merupakan daerah yang memiliki potensi perikanan cukup besar, yaitu perikanan laut, payau (tambak) dan perikanan tawar. Perikanan laut didukung oleh wilayah pesisir yang cukup luas di daerah Pantai Utara Laut Jawa. Produksi ikan hasil tangkapan oleh nelayan di Desa Ciparage Jaya dari tahun 2006 - 2008 cendrung menurun, produksi tahun 2006 sebesar 2.003.654 ton, tahun 2007 sebesar 1.211.094 dan tahun 2008 sebesar 653.903 ton. (Tempat Pelelangan Ikan Ciparage Jaya, 2009)
Potensi perikanan yang begitu besar harus didukung oleh pengaturan pengelolaan dan pemanfaatan yang tepat. Pengelolaan sumberdaya perikanan menuju ke arah yang lebih teratur didasarkan oleh adanya tekanan penangkapan (fishing pressure) yang berlebihan. Hal ini berkaitan dengan kepemilikan sumberdaya laut yang bersifat "open acces", yang berarti tidak adanya pengaturan tentang apa, kapan, dimana, siapa dan bagaimana sumberdaya alam dimanfaatkan, serta bagaimana terjadinya persaingan bebas (free for all). Hal ini dapat memicu terjadinya tragedy of the Commons, kerusakan sumberdaya, 
konflik antara pelaku dan kesenjangan ekonomi.

Mencermati bahwa pengelolaan perikanan sebagai suatu proses atau alur yang tidak terputus maka hal yang menjadi krusial adalah mengetahui status stok sumberdaya ikan (potensi dan tingkat pemanfaatan) melalui analisis data dan informasi yang kredibel. Informasi tentang sumberdaya ini selanjutnya menjadi dasar bagi pengendalian upaya penangkapan (effort) dalam rangka optimalisasi nilai ekonomi sumberdaya ikan sekaligus untuk memelihara keberlanjutannya. Di perairan wilayah tropis seperti di Indonesia, untuk mengetahui stok sumberdaya ikan tidaklah mudah oleh sebab sifat multispesies dan multigear perikanan tropis.

Untuk pendugaan stok ikan (standing stock), telah lama Schaefer (1957) mengembangkan metode surplus production yang mengkaji hubungan antara hasil tangkapan per satuan upaya atau CPUE (catch per unit effort). Ditemukan bahwa hubungannya linier dan trend-nya menurun (slope negatif). Schaefer mengembangkan konsep pertumbuhan populasi ikan berdasarkan asumsi konsep produksi biologi kuadratik yang dikembangkan Verhulst pada tahun 1983. Dari sini lahir konsep MSY (Maximum Sustainable Yield) yang akhirnya ditetapkan sebagai salah satu titik referensi (reference point) pengelolaan perikanan. Jelas bahwa untuk mengetahui status sumberdaya ikan di suatu perairan tidak cukup melihat MSY saja, diperlukan analisis tambahan seperti trend CPUE atau produktivitas usaha penangkapan di lapangan. Juga dapat digunakan indikator tambahan lainnya sebagaimana telah diuraikan Monintja (2006) tentang ciri-ciri perairan yang overfishing yaitu jumlah ikan hasil tangkapan berkurang, ukuran ikan yang tertangkap kecil, dan usaha tangkap untuk memperoleh hasil yang sama meningkat.

\section{Tujuan}

Tujuan penelitian ini adalah :

Mengetahui tingkat penangkapan maksimum lestari (Maximum Sustainable Yield) dan tingkat penangkapan yang maksimum secara ekonomis (Maximum Economic Yield) sumberdaya ikan pelagis di Pantai Ciparage Jaya.

\section{METODE PENELITIAN}

\section{Waktu dan Lokasi Penelitian}

Penelitian dilakukan di Perairan Ciparage Jaya, Kecamatan Tempuran Kabupaten Karawang. Waktu penelitian (pengumpulan data primer) adalah bulan Juni - Agustus 2009.

\section{Metode Pengambilan Data}

Metode yang digunakan dalam penelitian ini adalah metode survei. Metode survei bertujuan untuk mengumpulkan data dari sejumlah variabel pada suatu kelompok masyarakat melalui wawancara langsung dan berpedoman pada daftar pertanyaan yang telah dipersiapkan sebelumnya. Data yang dikumpulkan adalah data primer dan data sekunder.

Data primer diperoleh dengan mengadakan observasi langsung ke lokasi penelitian dan melakukan wawancara dengan pemilik mini purse seine, nakhoda 
(fishing master) dan anak buah kapal (ABK) dengan menggunakan kuesioner. Satuan penelitian adalah unit penangkapan mini purse seine. Data primer ini mencakup data unit penangkapan, fishing base, fishing ground, metode penangkapan ikan, data produksi dan faktor-faktor produksi mini purse seine, dan harga ikan hasil tangkapan.

Jumlah unit penangkapan mini purse seine yang ada di Ciparage Jaya tahun 2009 adalah sebanyak 125 unit yang dimiliki oleh 110 orang. Penentuan responden dilakukan dengan teknik purposive sampling. Jumlah responden yang diambil sebanyak 110 orang terdiri dari 34 pemilik kapal (30\%), 38 nakhoda (30\%) dan 38 orang ABK mini purse seine.

Data sekunder yang diperlukan adalah data berkala (time series) hasil tangkapan dan upaya penangkapan mini pure seine selama lima tahun terakhir (2003-2008) dan data penunjang lainnya. Data ini diperoleh dari instansi terkait, yaitu Tempat Pelelangan Ikan Ciparage Jaya, KUD Singaperbangsa dan Dinas Perikanan Kabupaten Karawang.

\section{Metode Analisa Data}

Metode analisis data yang digunakan adalah analisis deskriptif kuantitatif. Analisa data yang dilakukan dalam penelitian ini adalah analisis terhadap parameter biologi dan ekonomi. Parameter biologi dianalisis dengan menghitung jumlah stok sumberdaya perikanan di perairan Ciparage Jaya dengan menggunakan metode surplus produksi, parameter ekonomi dengan menggunakan model bionomic GordonSchaefer.
Analisa data yang dilakukan pada penelitian ini didasarkan pada batasanbatasan : Potensi sumberdaya ikan yang terdapat di daerah penelitian dihitung berdasarkan hasil tangkapan kapal yang menangkap jenis hasil tangkapan yang sama di Perairan Ciparage Jaya (purse seine). Perhitungan stok sumberdaya perikanan di daerah penelitian dihitung dengan pendekatan model surplus produksi Schaefer (1957). Kapal mini purse seine yang diteliti adalah kapal yang fishing basenya di Desa Ciparage Jaya dan beroperasi di perairan Ciparage jaya. Maximum Sustainable Yield (MSY) merupakan indikator jumlah tangkapan maksimum secara lestari. Maximum Economic Yield (MEY) merupakan indikator titik keuntungan maksimum secara ekonomi

\section{Pendugaan Parameter Biologi}

Pendugaan parameter biologi ini dilakukan menggunakan metode surplus produksi. Metode surplus produksi adalah metode yang digunakan untuk menghitung potensi lestari (MSY) dan upaya optimum dengan cara menganalisa hubungan upaya tangkap (E) dengan hasil tangkap per unit upaya tangkap (CPUE) pada suatu perairan dengan data time series. Data yang digunakan berupa hasil tangkap (catch) dan upaya tangkap (effort).

Menurut Scheafer (1957) dalam Sparre P. dan Venema S.C. (1999), hubungan hasil tangkap (catch) dengan upaya tangkap (effort) adalah :

$$
C=a E+b E^{2} \ldots \ldots \ldots \ldots 1
$$

dimana : $\mathrm{a}=$ intercept

$$
\mathrm{b}=\text { slope }
$$

$\mathrm{C}=$ total hasil tangkapan 


$$
\mathrm{E}=\text { total upaya penangkapan }
$$

Sedangkan hubungan CPUE dengan upaya tangkap adalah:

$$
C P U E=a+b E \ldots \ldots 2
$$

Upaya tangkap optimum dihitung dengan menurunkan persamaan 1 terhadap upaya tangkap ;

$$
\begin{aligned}
& \frac{d C}{d E}=a+2 b E \\
& 0=a+2 b E \\
& -2 b E=a \\
& E_{o p t}=-\frac{a}{2 b} \ldots
\end{aligned}
$$
. .3

dimana $E_{o p t}=$ upaya penangkapan optimum

Penghitungan nilai MSY dilakukan dengan memasukkan persamaan 3 ke dalam persamaan 1 sehingga diperoleh kondisi MSY :

$$
C_{M S Y}=-\frac{a^{2}}{4 b}
$$

dimana $C_{M S Y}=$ total hasil tangkapan pada kondisi lestari maksimum

C adalah hasil tangkapan ikan (catch), yaitu keseluruhan hasil tangkapan suatu jenis ikan, sedangkan $\mathrm{E}$ adalah upaya penangkapan ikan (effort), yaitu keseluruhan jumlah upaya penangkapan ikan yang digunakan menangkap suatu jenis ikan tertentu. Biasanya untuk menunjukkan upaya penangkapan yang dimaksud digunakan jumlah trip penangkapan suatu armada penangkapan ikan. Akan tetapi bila jumlah trip penangkapan sulit ditemukan, maka dapat dipergunakan jumlah armada penangkapan ikan. Kelemahannya adalah tidak bisa menggambarkan berapa banyak upaya penangkapan yang dilakukan setiap kapal.

Pada penelitian ini upaya penangkapan didekati dengan perhitungan jumlah trip per unit kapal mini purse seine, yaitu sebanyak 20 trip dalam sebulan selama 8 (delapan) bulan per tahun atau sama dengan 160 trip/tahun/unit.

\section{Pendugaan Parameter Ekonomi}

Model Gordon Schaefer digunakan untuk menganalisis model bioekonomi purse seine. Model bioekonomi yang digunakan adalah model bioekonomi statik dengan harga tetap. Model ini disusun dari model parameter biologi, biaya operasi penangkapan dan harga ikan. Asumsi yang dipergunakan dalam model statik Gordon Schaefer ini adalah harga ikan per $\mathrm{kg}$ (p) dan biaya penangkapan per unit upaya tangkap adalah konstan (Fauzi A., 2004). Total penerimaan nelayan dari usaha penangkapan (TR) adalah :

$$
T R=p . C
$$

dimana :

$$
\begin{aligned}
\boldsymbol{T R}= & \text { total revenue }(\text { penerimaan total }) \\
p= & \text { harga rata-rata ikan hasil survey } \\
& \text { per } \mathrm{kg}(\mathrm{Rp}) \\
C= & \text { jumlah produksi ikan }(\mathrm{kg})
\end{aligned}
$$

Total biaya penangkapan (TC) dihitung dengan persamaan :

$$
T C=c . E
$$

dimana :

$$
\begin{gathered}
T C=\text { total cost (biaya penangkapan } \\
\text { total) } \\
c=\text { total pengeluaran rata-rata unit } \\
\text { penangkapan ikan (Rp) } \\
E=\text { jumlah upaya penangkapan untuk } \\
\text { menangkap sumberdaya ikan (unit) }
\end{gathered}
$$


Sehingga keuntungan bersih usaha penangkapan ikan $(\mathrm{N})$ adalah:

$$
\begin{aligned}
& \pi=T R-T C \\
& \pi=p \cdot C-c . E \\
& \pi=p\left(a E-b E^{2}\right)-c E
\end{aligned}
$$

\section{HASIL DAN PEMBAHASAN}

\section{Potensi Lestari Sumberdaya Ikan Pelagis Kecil}

Hasil tangkapan ikan pelagis kecil di perairan Ciparage Jaya dalam lima tahun terakhir (2004-2008) berfluktuasi sebagaimana terlihat pada Tabel 1. Hal ini dapat diakibatkan oleh berbagai faktor yang saling berinteraksi dalam kegiatan penangkapan ikan, Faktor tersebut adalah upaya penangkapan dan ketersediaan stok ikan di perairan Ciparage Jaya. Produksi dan upaya yang menunjukkan nilai tertinggi, terjadi pada tahun 2008, yaitu pada tingkat upaya 14.830 trip dan memperoleh hasil sebesar $2.950 .000 \mathrm{~kg}$

Tabel 1. Total produksi, upaya penangkapan dan CPUE unit penangkapan

\begin{tabular}{|c|c|c|c|}
\hline Tahun & Total Produksi (kg) & Upaya (trip) & CPUE (kg/trip) \\
\hline 2004 & 2.330 .000 & 8.689 & 268,16 \\
\hline 2005 & 2.442 .000 & 9.493 & 257,23 \\
\hline 2006 & 2.940 .000 & 11.172 & 263,16 \\
\hline 2007 & 2.770 .000 & 12.767 & 216,96 \\
\hline 2008 & 2.950 .000 & 14.830 & 198,92 \\
\hline
\end{tabular}

Sumber : TPI Ciparage, 2009

Upaya penangkapan dari tahun 2004-2008 cenderung meningkat dan nilai CPUE befluktuasi, nilai CPUE tertinggi terjadi pada tahun 2004 sebesar 268,16 $\mathrm{kg} /$ trip dan terendah tahun 2008 sebesar 198,92 kg/trip. Nilai CPUE ini mencerminkan produktivitas alat tangkap yang digunakan dalam menangkap ikan pelagis kecil di perairan Ciparage Jaya.

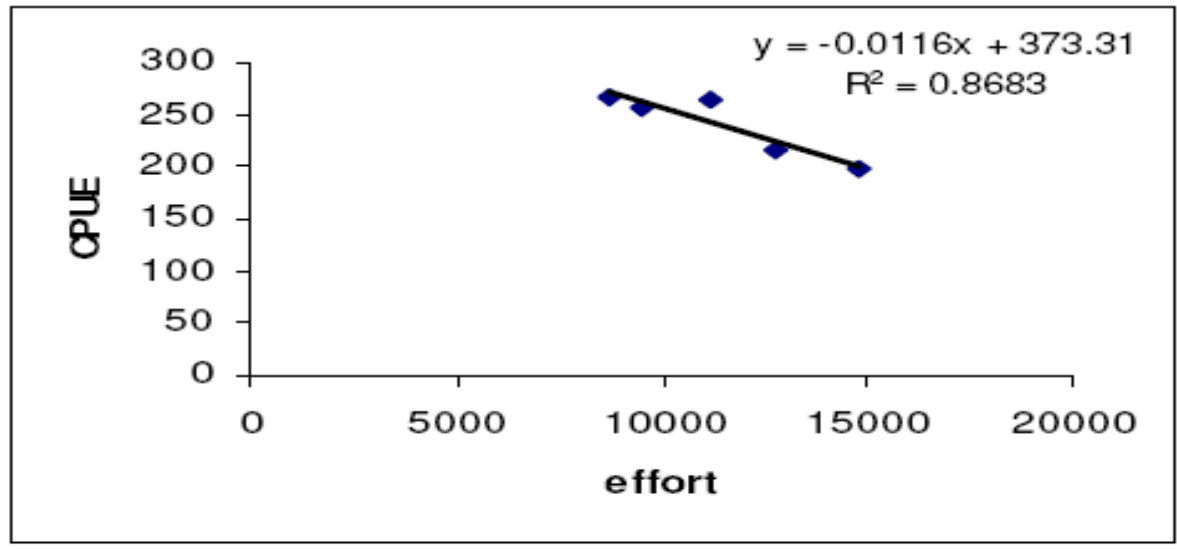

Gambar 1. Grafik hubungan CPUE dengan effort 
Nilai CPUE dengan upaya penagkapan (effort) perlu diketahui korelasinya sehingga dapat diketahui kecendrungan produktivitas alat tangkap ikan pelagis kecil yang dicerminkan oleh CPUE pada Gambar 1. Korelasi antara CPUE dengan effort menunjukan hubungan negatif, yaitu semakin tinggi upaya penangkapan (effort) semakin rendah nilai CPUE. Korelasi negatif antara CPUE dengan upaya penangkapan mengindikasikan bahwa produktifitas alat tangkap ikan pelagis kecil akan menurun apabila upaya penangkapan mengalami peningkatan.

Fungsi produksi lestari merupakan hubungan antara hasil tangkapan per upaya (y) dengan upaya penangkapan (x) dalam bentuk kuadratik. Tingkat upaya penangkapan (x) maupun hasil tangkapan yang diperoleh dari hubungan tersebut tidak akan mengancam kelestarian sumberdaya perikanan (menggambarkan keberlanjutan sumberdaya).
Berdasarkan pengolahan data yang dilakukan diperoleh nilai CPUE ikan pelagis kecil di perairan Ciparage Jaya dapat digambarkan yaitu sebesar 373.310.011E, ini menunjukkan bahwa setiap penambahan upaya penangkapan sebesar satuan E maka akan menurunkan CPUE sebesar 0.0116 ton kali satuan E.

Perhitungan matematis hasil tangkapan pada kondisi MSY diperoleh sebesar 2.996.716,616 kg/th. Nilai MSY menunjukan maksimum lestari yaitu hasil tangkapan ikan pelagis kecil tertinggi yang dapat ditangkap di perairan Ciparage Jaya. Pemanfaatan sumberdaya perikanan di perairan Ciparage Jaya berdasarkan hasil perhitungan tersebut menggambarkan bahwa tingkat pemanfaatan yang dilakukan nelayan masih berada di bawah batas maksimum lestari.

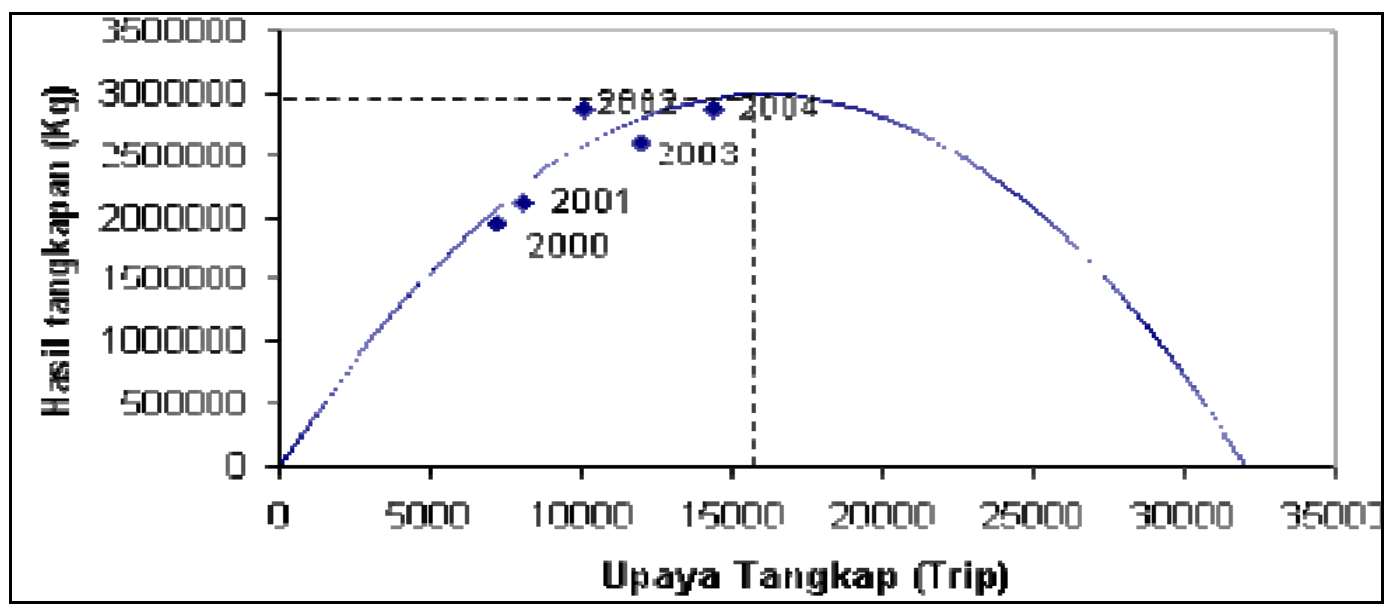

Gambar 2. Hubungan hasil tangkapan dan upaya penangkapan

Hubungan kuadratik antara upaya penangkapan dengan hasil tangkapan ikan pelagis kecil dapat dilihat pada Gambar 2. Berdasarkan gambar diatas terlihat bahwa hubungan antara upaya penangkapan dan hasil penangkapan ikan berbentuk parabola, artinya setiap penambahan tingkat upaya penangkapan 
(E) maka akan meningkatkan hasil tangkapan (h) sampai mencapai titik maksimum, kemudian akan terjadi penurunan hasil tangkapan untuk tiap peningkatan intensitas pengusahaan sumberdaya.

\section{Analisis Bio-Ekonomi Perikanan Pelagis Kecil}

Analisis bio-ekonomi dengan pendekatan secara biologi dan ekonomi merupakan salah satu alternatif pengelolaan yang dapat diterapkan demi upaya optimalisasi pengusahaan sumberdaya ikan secara berkelanjutan. Optimalisasi bio-ekonomi yang dilakukan dalam penelitian ini mengikuti Model Gordon-Schaefer.

Hasil tangkapan menunjukan produksi ikan pelagis kecil yang dihasilkan pada tingkat upaya tertentu.
Pada saat penangkapan masih rendah, peningkatan tingkat upaya akan diikuti oleh peningkatan penerimaan usaha hingga mencapai keseimbangan secara ekonomi. Disisi lain biaya penangkapan akan meningkat seiring dengan meningkatnya tingkat upaya penangkapan. Total penerimaan diperoleh dari hasil perkalian antara harga nominal dengan hasil tangkapan, sedangkan total biaya penangkapan per trip diperoleh dari biaya penangkapan per trip. Rente ekonomi (keuntungan) merupakan selisih antara total penerimaan dengan total biaya untuk melakukan trip penangkapan sebesar tingkat upaya penangkapan masingmasing kondisi. Perbandingan kondisi MSY, MEY dapat dilihat pada Tabel 2.

Tabel 2. Hasil analisis bio-ekonomi sumberdaya perikanan pelagis kecil di perairan Ciparage Jaya.

\begin{tabular}{|c|c|c|c|c|c|}
\hline $\begin{array}{c}\text { Kondisi } \\
\text { Pengelolaan }\end{array}$ & $\begin{array}{c}\text { Effort } \\
(\text { trip})\end{array}$ & $\begin{array}{c}\text { Produksi } \\
(\mathrm{kg})\end{array}$ & $\begin{array}{c}\text { Total } \\
\text { Penerimaan } \\
(\mathrm{Rp})\end{array}$ & $\begin{array}{c}\text { Total Biaya per } \\
\text { trip (Rp) }\end{array}$ & Rente Ekonomi \\
\hline Aktual & 11.390 & $2.686 .400,0$ & 16.118 .400 & 5.114 .110 .000 & 11.004 .290 .000 \\
MSY & 16054 & $2.996 .716,6$ & 17.980 .299 .701 & 7.208 .563 .591 & 10.771 .736 .110 \\
MEY & 12836 & $2.876 .299,2$ & 17.257 .795 .220 & 5.763 .554 .614 & 11.494 .240 .600 \\
Open Acces & 25.672 & $1.921 .184,9$ & 1.152 .710 .923 & 1.152 .710 .922 & 0 \\
\hline
\end{tabular}

Tabel 2 di atas memperlihatkan bahwa dengan pendekatan bio-ekonomi, maka produksi hasil tangkapan pada kondisi aktual sebesar $2.686 .400 \mathrm{~kg} / \mathrm{th}$ telah mendekati batasan produksi di tingkat MEY sebesar 2.876.292,2 kg/th, sehingga peluang pemanfaatanya relatif kecil $(189.899,20 \mathrm{~kg} / \mathrm{th})$. Hasil tangkapan yang diperoleh pada kondisi pengusahan sumberdaya MSY di Perairan Ciparage
Jaya tahun 2004-2008 sebesar 2.996.716,60 kg. Hasil tangkapan tersebut lebih besar jika dibandingkan dengan hasil tangkapan yang didapat pada pengusahaan MEY sebesar 2.876.299,20 kg. Hasil tangkapan ikan pelagis pada kondisi MSY adalah kondisi hasil tangkapan yang maximum lestari dimana jika hasil tangkapan sudah melebihi kondisi hasil tangkapan ini maka mengakibatkan 
sumberdaya perikanan tersebut menjadi tidak sustin.

Rata-rata upaya penangkapan yang dilakukan pada tingkat open access sebesar 25.672,00 trip. Upaya penangkapan tersebut lebih besar jika dibandingkan dengan upaya penangkapan yang dilakukan pada tingkat produksi $M S Y$ yakni 16.054,00 trip dan pada tingkat produksi MEY yaitu $12.836,00$ trip. Besarnya tingkat upaya penangkapan pada kondisi open access dikarenakan siapa saja boleh melakukan kegiatan penangkapan.

Rente ekonomi tertinggi yang diperoleh nelayan adalah pada tingkat produksi $M E Y$ yaitu sebesar Rp11.494.240.600,00 dan pada tingkat MSY sebesar 10.771.736110,00. Berkurangnya nilai rente ekonomi akan terus berlangsung hingga dicapai keuntungan normal yaitu pada saat tingkat upaya penangkapan yang dilakukan mencapai keseimbangan open access ( $\mathrm{p}=$ 0 ). Jika terjadi peningkatan upaya penangkapan melebihi kondisi ini maka akan mengakibatkan kerugian bagi nelayan.

Pada pengelolaan open access, meskipun total penerimaan semakin menurun, selagi total penerimaan masih lebih besar dari total biaya penangkapan (rente ekonomi positif), maka kondisi ini akan tetap dijalankan oleh nelayan untuk bertahan dalam usaha penangkapan, dimana nelayan akan meningkatkan effort. Jika tingkat effort sudah berlebihan, sehingga total penerimaan lebih kecil dari total biaya penangkapan, maka sebagian pelaku perikanan akan keluar dari kegiatan penangkapan tersebut, yang berarti menurunkan effort. Dengan demikian titik keseimbangan open access akan terjadi pada saat total penerimaan sama dengan total biaya penangkapan atau rente ekonomi sama dengan nol.

Pada Gambar 3 dapat dilihat grafik bio-ekonomi hubungan total penerimaan dan biaya penangkapan kegiatan pengelolaan perikanan pelagis kecil. Dengan adanya keuntungan dalam pengelolaan sumberdaya menjadi pendorong bagi nelayan untuk mengembangkan armada penangkapan maupun upaya penangkapan dengan tujuan untuk memperoleh keuntungan sebanyak-banyaknya. 


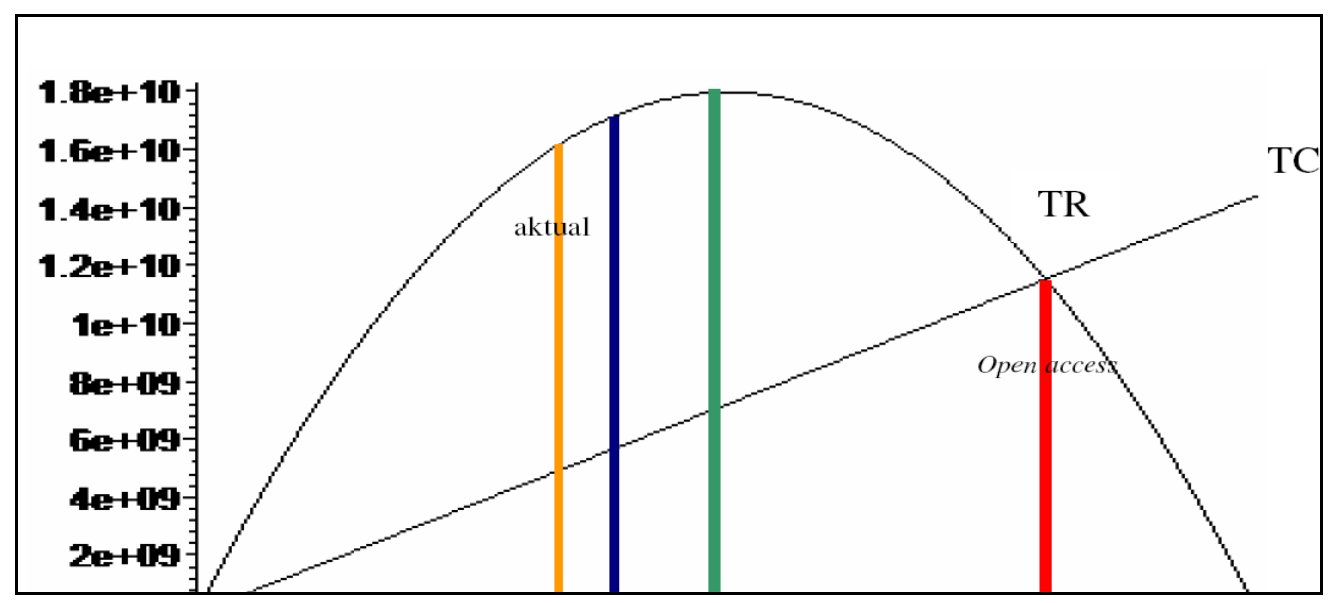

Gambar 3. Keseimbangan bioekonomi Gordon-Schaefer untuk pengelolaan perikanan pelagis kecil di Ciparage jaya.

Dengan diketahui nilai Maximum Economic Yield (MEY) pelagis kecil diperairan Ciparage Jaya, maka tingkat pemanfaatan pada tahun terakhir dapat diketahui. Nilai MEY sebesar 2.876.299 $\mathrm{kg}$ dengan jumlah hasil tangkapan pada tahun terakhir sebesar $2.686 .400 \mathrm{~kg}$, maka tingkat pemanfaatan diperoleh sebesar 93,40 \%. Hal ini menunjukan bahwa peluang untuk memanfaatkan sumberdaya pelagis kecil sisa sedikit berkisar 7,6\%.

\section{KESIMPULAN}

1. Tingkat penangkapan maximum lestari (MSY) ikan pelagis kecil di perairan Ciparage Jaya adalah 2.996.716,6 kg/th, dan tingkat penangkapan yang maximu secara ekonomis (MEY) adalah $2.876 .299 \mathrm{~kg} / \mathrm{th}$.

2. Tingkat penangkapan nelayan ratarata $2.686 .400 \mathrm{~kg} / \mathrm{th}$, berdasarkan potensi lestarinya (MSY) dan segi ekonomi (MEY) mendekati nilai optimum, sehingga tidak memungkinkan peningkatan upaya penangkapan dilakukan.
3. Usaha (strategi) yang dapat dilakukan untuk meningkatkan taraf hidup keluarga nelayan adalah perbaikan dan peningkatan kualitas alat tangkap, sistem pasar yang dapat menjaga kesetabilan harga, pengolahan ikan yang memberikan nilai tambah pada produksi perikanan, dan alternative usaha budidaya.

\section{DAFTAR PUSTAKA}

Dahuri R. 2003. Keanekaragaman Hayati Laut: Aset Pembangunan Berkelanjutan Indonesia. PT. Gramedia Pustaka Utama. Jakarta

Effendie, M.I. 1997. Biologi Perikanan. Yayasan Pustaka Nusantara.Yogyakarta.

Fauzi A. 2004. Ekonomi Sumberdaya Alam dan Lingkungan: Teori dan Aplikasi. Gramedia Pustaka Utama. Jakarta. 
Nikijuluw V.P.H., dkk. 2007. Sistem Sparre P. dan Venema S.C. 1999.

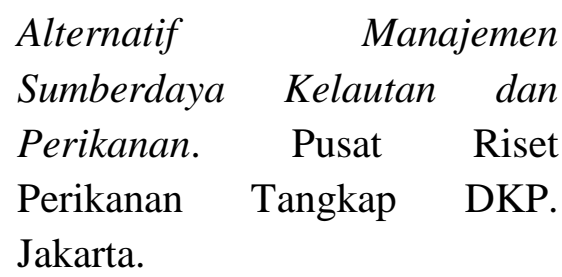

Introduksi Pengkajian Stok Ikan

Tropis. FAO. Jakarta.

Jakarta. 